\title{
CORRESPONDENCE
}

\section{Nuclear Defence}

SIR,--I supported wholeheartedly your editorial "France should not test" (Nature, 243, $50 ; 1973$ ), but I think that perhaps you were a little unfair in your remark that the French Government would be well advised to admit that its force de frappe is no more than an illusion.

I would, of course, agree that for its advertised purpose as a contribution to the defence of Europe against possible Soviet aggression, its short range and small size make it utterly insignificant if the United States is involved, and, of course, like our nuclear force, more likely to induce preventive attack than to act as a defence if the Russians could be sure that the Americans would not be involved.

I am surprised, however, that you have taken its advertised object at its face value, rather than as the window dressing which it seems to me to be. It is surely easy to believe that the real concern of the French general staff is still, as it has always been, with Germany rather than with Russia. This is not even any reflexion on the general well-meaningness of the present West German Government. Governments have changed in this respect in the past, and anyway, general staffs concern themselves with what is possible rather than with what governmental intentions are likely to be. Without nuclear weapons France could offer little resistance to a revanchist Germany and might well doubt the willingness of the United States to destroy such a Germany on behalf of France, and in doing so, destroy their main bulwark in Europe against the USSR.

Ludicrously inadequate as it would be in face of a Russian attack, the force de frappe is in both range and power entirely adequate as a deterrent to a Germany which does not possess such nuclear weapons. One could well blame the French general staff for taking the same narrow and limited view of their country's interests as is taken by all other national general staffs, but I think that it is unfair to blame them for suffering from illusions.

Yours faithfully,

\section{J. H. FREMLIN}

Department of Physics,

Chancellor's Court,

The University of Birmingham,

PO Box 363, Birmingham B15 $2 T T$

\section{Reaching for the Stars}

SiR,-I feel obliged to respond to the two articles "Eye on the Future" and "The Search for Signals from Extraterrestrial Civilizations" (Nature, 241, 363 and $379 ; 1973)$.

The first of these, an excellent brief review of the Project Cyclops report*, ends by questioning the cost and value of the search for extraterrestrial intelligence: "The scale of expenditure suggested for Cyclops, however, runs at four times the total annual expenditure of the British Science Research Council. Perhaps the question is whether it is more efficient or more satisfying to spend $\$ 600$ million a year asking the stars for, say, a cure for cancer or to spend the same sum on cancer research on Earth." These peculiar comparisons ignore the difference in the potential support base and imply that a cure for cancer would be a major, if not the only, benefit of interstellar contact. Ideally Cyclops would be an international effort; but even excluding this possibility, the $\$ 600$ million/year (during the construction phase only) is only 8 per cent of the 1966 US space budget and 20 per cent of that for 1973.

Conceivably a cancer cure could be discovered out of interstellar contact (assuming our biochemistry is not too different from theirs), but is only one of a host of potential benefits, many of which may be far more important. Any civilization we contact will be at least as advanced as we and probably much more so. In all probability they will have faced and solved many of the problems that beset the world today such as pollution, depletion of natural resources, population control and the assurance of continued genetic evolution in a compassionate society, to name only a few.

Present theories of galactic evolution and of the origin and evolution of life support the belief that intelligent civilizations have existed in our Galaxy for a few billion years. Interstellar communication may therefore also have existed for aeons, and our first contact could put us in touch, not with another isolated civilization, but with this galactic community. We would then have access to a galactic heritage of knowledge that might include, in addition to a five billion year pictorial record

* Copies available from John Billingham NASA/Ames Research Center Code LT, Moffett Field, California 94305. of the universe, the Galaxy, and its life forms, some insight into the common cause of intelligent life and its future role. Interstellar contact may well mean childhood's end for the human race. With what other outcome can this be compared?

In the second article James C. G. Walker analyses the consequences of using a type of search strategy that was known to be inadequate before the Cyclops study began. Walker rejects omnidirectional beacons on the grounds that "the power requirement of an isotropic call signal detectable at 100 light years is approximately equal to the world's present total power consumption". He then assumes beamed beacons that illuminate any particular receiver for a short fraction of the time and, not surprisingly, arrives at very pessimistic figures for probable search time. The Cyclops study assumes that the total cost of achieving contact should be minimized by balancing the costs of transmitting and receiving. This leads to receiving antennas several $\mathrm{km}$ in diameter, which can be realized as filled phased arrays. Omnidirectional beacons are then quite feasible and with these the search times are greatly reduced as indicated in Table 1.

Table 1 Search Times for Galaxies, using Walker and Cyclops Strategies

\section{Average separa- tion of com- municative civilizations 24 light yr 240 light $y r$ 2,400 light yr

$$
\begin{array}{ll}
\text { Duration of search } \\
\text { Walker } & \text { Cyclops } \\
\text { strategy } & \text { strategy }
\end{array}
$$$$
14 \text { centuries } \quad 1 \mathrm{~d} \dagger
$$$$
14 \text { million yr } \quad 1 \mathrm{yr}
$$$$
140 \text { aeons }+\quad 370 \mathrm{yr}
$$

$\dagger$ Needed to get complete sky coverage; otherwise $8 \mathrm{~h}$.

¥ Should be reduced, galactic disk is only about 1,500 light yr thick in solar neighbourhood.

A Cyclops receiving system with an effective clear antenna aperture of $5 \mathrm{~km}$ would detect in $1,000 \mathrm{~s}$ a coherent signal having an incident flux of 5 photons $\mathrm{s}^{-1}$ mile ${ }^{-2} \S$. It would detect a 16 megawatt omnidirectional beacon at 100 light years or a 1,600 megawatt one at 1,000 light years range. Even this latter beacon radiates less than one fourthousandth of the world's present power

$\S$ Since these are $1.5 \mathrm{GHz}$ photons an optical system of equal power sensitivity would have to be able to detect one photon $\mathrm{s}^{-1} /$ hundred thousand square miles. 
consumption from fossil fuels, and could be powered with a single modern nuclear plant. Man will qualify for participation in the galactic community when he is willing to invest his share in a balanced system, rather than expecting the other civilizations to do the whole job.

Yours faithfully,

\section{B. M. Oliver}

\section{Plus ça Change}

SIR,-Important decisions about the future development of atomic power must frequently be made by people who do not necessarily have an intimate knowledge of the technical aspects of reactors. These people are, nonetheless, interested in what a reactor plant will do, how much it will cost, how long it will take to build and how long and how well it will operate. When they attempt to learn these things, they become aware of confusion existing in the reactor business. There appears to be unresolved conflict on almost every issue that arises.

I believe that this confusion stems from a failure to distinguish between the academic and the practical. These apparent conflicts can usually be explained only when the various aspects of the issue are resolved into their academic and practical components. To aid in this resolution, it is possible to define in a general way those characteristics which distinguish the one from the other.

An academic reactor or reactor plant almost always has the following basic characteristics: (1) It is simple. (2) It is small. (3) It is cheap. (4) It is light. (5) It can be built very quickly. (6) It is very flexible in purpose ("omnibus reactor"). (7) Very little development is required. It will use mostly "off-theshelf" components. (8) The reactor is in the study phase. It is not being built now.

On the other hand, a practical reactor plant can be distinguished by the following characteristics: (1) It is being built now. (2) It is behind schedule. (3) It is requiring an immense amount of development on apparently trivial items. Corrosion, in particular, is a problem. (4) It is very expensive. (5) It takes a long time to build because of the engineering development problems. (6) It is large. (7) It is heavy. (8) It is complicated.

The tools of the academic-reactor designer are a piece of paper and a pencil with an eraser. If a mistake is made, it can always be erased and changed. If the practical-reactor designer errs, he wears the mistake around his neck ; it cannot be erased. Everyone can see it.

The academic-reactor designer is a dilettante. He has not had to assume any real responsibility in connexion with his projects. $\mathrm{He}$ is free to luxuriate in elegant ideas, the practical shortcomings of which can be relegated to the category of "mere technical details". The practical-reactor designer must live with these same technical details. Although recalcitrant and awkward, they must be solved and cannot be put off until tomorrow. Their solutions require manpower, time and money.

Unfortunately for those who must make far-reaching decisions without the benefit of an intimate knowledge of reactor technology and unfortunately for the interested public, it is much easier to get the academic side of an issue than the practical side. For a large part those involved with the academic reactors have more inclination and time to present their ideas in reports and orally to those who will listen. Since they are innocently unaware of the real but hidden difficulties of their plans, they speak with great facility and confidence. Those involved with practical reactors, humbled by their experiences, speak less and worry more.

Yet it is incumbent on those in high places to make wise decisions, and it is reasonable and important that the public be correctly informed. It is consequently incumbent on all of us to state the facts as forthrightly as possible. Although it is probably impossible to have reactor ideas labelled as "practical" or "academic" by the authors, it is worth while for both the authors and the audience to bear in mind this distinction and to be guided thereby.

$$
\text { Yours faithfully, }
$$

\section{H. G. Rickover}

This previously unpublished comment on the practical problems of nuclear power was originally written in $j$ une 1953 but is thought still to be relevant today.--Editor, Nature.

\section{Announcements}

\section{International Meetings}

June 13, Radioisotopes in Haematology (General Secretary, The British Institute of Radiology, 32 Welbeck Street, London W1M 7PG).

June 14, X-ray Image Intensifier Systems (General Secretary, Institution of Electronic and Radio Engineers, 8 Bedford Square, London WC1B 3RG).

\section{HOW TO BUY NATURE}

The cost of one year's subs:aription to NATURE is:

UK \& elsewhere US \& Canada

Nature (Friday) f16

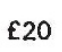

Nature \& Nature Physical Science or Nature New Biology $£ 24$ £33

Nature New Biology or Nature Physical Science £10 $£ 15$ All three editions $£ 29.50$ f44 Index (1972) E1 $£ 1.50$

(Charges for delivery by air mail on application). Subscribers in North America may be able to claim a tax rebate against their NATURE subscription.
Editorial, Advertising and Publishing Offices of NATURE MACMILLAN JOURNALS LIMITED 4 LITTLE ESSEX STREET, LONDON WC2R 3LF Telephone Number: 01-836 6633. Telegrams: Phusis Londor: WC2R 3LF Telex 262024

MACMILLAN JOURNALS LIMITED 711 NATIONAL PRESS BUILDING WASHINGTON DC 20004

T.ephone Number: 202-737 2355. Telex 64280

International Advortisement Manager PETER R. KAVANAGH MACMILLAN JOURNALS LINIITED 4 LITTLE ESSEX STREET, LONDON WC2R 3LF Telephone Numbers: UK 01-836 6633 USA 202-737 2355

Subscription Department MACMILLAN JOURNALS LIMITED BRUNEL ROAD, BASINGSTOKE, HANTS RG21 2XS Telephone Number: Basingstoke 29242 Classified advertisements T. G. SCOTT \& SON, LIMITED 1 CLEMENT'S INN, LONDON WC2A 2ED Telephone Number: 01-242 6264/01-405 4743 Telegrams: Textualist London WC2A 2ED

Registered as a newspaper at the Post Office 